\title{
Pelatihan Pembuatan Jam Digital dan Lampu Hias LED dengan Arduino Di Pesantren Daarussalaam
}

\author{
M. Imbarothur Mowaviq ${ }^{1}$; Sugeng Purwanto ${ }^{2}$; Andi Junaidi ${ }^{3}$; Wawan Ridwan ${ }^{4}$; \\ Sofitri Rahayu ${ }^{5}$; Hasna Satya Dini ${ }^{6 ;}$ Rudina Okvasari $^{7}$ \\ 1,2,3,4,5, ${ }^{\text {Sekolah Teknik Tinggi PLN }}$ \\ ${ }^{1}$ mowaviq@sttpln.ac.id
}

\begin{abstract}
Islamic boarding schools in Indonesia are important as an institution that develop religion, people's intelligence, and morality. In other words, Islamic boarding schools have purpose as institutions that mantain Islamic values by focusing education aspects. At the same time, education cannot be separated with technology as supporting of learning system. By technological development, one of them is a microcontroller, santri must be able to understand the technology in order to fall not behind. Arduino is a microcontroller that is assembled in one board and has software that can be accessed for free. Arduino is designed to facilitate electromechanical application in various activities. The microcontroller that is used on Arduino is Atmel AVR type with supporting components. The aim of this training is students from the Daarussalaam Islamic Boarding School can improve their knowledge of the latest technology, especially about microcontrollers. They also can make decorative lights from LEDs and digital clocks. Schools can also use it for practical activities in schools that are directly assisted by their teachers.
\end{abstract}

Keywords: Training, Digital Clock, LED Decorative Light, Arduino, Islamic Boarding School

\begin{abstract}
ABSTRAK
Pondok pesantren di Indonesia memiliki peranan penting sebagai lembaga penyebaran agama sekaligus keceradasan rakyat dan moral bangsa. Dapat dikatakan bahwa pondok pesantren memiliki tujuan sebagai institusi yang mempertahankan nilai-nilai keislaman dengan titik berat pada aspek pendidikan. Sedangkan dalam dunia pendidikan sendiri, aspek teknologi tidak bisa dipisahkan sebagai penunjang sistem belajar. Dengan perkembangan teknologi, salah satunya mikrokontroler, santri haruslah dapat mengenali teknologi tersebut agar tidak tertinggal. Arduino merupakan mikrokontroler yang dirakit dalam satu papan dan memiliki perangkat lunak yang dapat diakses secara gratis. Arduino dirancang untuk memudahkan penggunaan elektromekanik dalam berbagai kegiatan. Mikrokontroler yang digunakan pada Arduino berjenis atmel AVR yang dilengkapi komponen pendukung. Tujuan dari kegiatan ini adalah agar santri dari Pondok Pesantren Daarussalaam dapat meningkatkan pengetahuannya tentang teknologi terbaru, terutama tentang mikrokontroler. Mereka juga dapat membuat secara mandiri lampu hias dari led dan juga jam digital. Sekolah juga dapat menggunakannya untuk kegiatan praktek di sekolah yang didampingi secara langsung oleh guru.
\end{abstract}

Kata kunci: Pelatihan, Jam Digital, Lampu Hias LED, Arduino, dan Pesantren 


\section{PENDAHULUAN}

Perkembangan teknologi saat ini sudah sangat pesat dan seolah telah menjadi bagian tak terpisahkan dari kehidupan manusia. Teknologi dalam bidang elektronika adalah salah satu yang paling pesat perkembangannya dibanding bidang lain. Salah satu bidang yang banyak memakai teknologi elektronika adalah bidang hiburan. Berbagai macam hiburan mulai dari televisi, radio, video game dan berbagai macam hiburan lainnya bisa dipastikan memakai teknologi elektronik di dalamnya. Namun tidak menuntut kemungkinan juga ketika bidang teknologi diterapkan untuk meningkatkan kualitas dunia pendidikan.

Berkembangnya ilmu pengetahuan dan teknologi yang sangat maju pada masa sekarang diikuti oleh sebagian bahkan hampir semua kalangan. Selain itu, perkembangan sistem yang umumnya berbasis komputer dan sistem terkontrol yang menggunakan mikrokontroller sudah sangat maju. Sebagai penunjang dalam peningkatan keamanan yang semakin besar. Pengontrolan peralatan elektronika telah menghasilkan metode yang sangat maju seiring dengan perkembangan teknologi. Perkembangan tersebut dapat dilihat pada pembuatan aplikasi teknologi sederhana menggunakan mikrokontroller seperti pembuatan aplikasi LED, simulasi lampu lalu lintas, dan masih banyak lagi.

Salah satu jenis miktrokroler yang saat ini banyak digunakan adalah Arduino. Arduino merupakan mikrokontroller yang dirakit dalam satu papan dan memiliki perangkat lunak yang dapat diakses secara gratis. Arduino dirancang untuk memudahkan penggunaan elektromekanik dalam berbagai kegiatan. Mikrokontroller yang digunakan pada Arduino berjenis atmel AVR dengan berbagai jenis lainnya. Perangkat lunak arduino dapat dijalankan pada sistem operasi Windows, Macintosh OSx dan Linux [1]. Arduino adalah sebuah produk dengan desain sistem minimum dari mikrokontroler yang dibuka secara bebas [2]. Arduino dirancang agar mudah digunakan untuk pemula yang memilikinya tidak ada pengalaman perangkat lunak atau elektronik. Dengan Arduino, pengguna bisa membangun objek yang bisa merespon dan/atau mengontrol cahaya, suara, sentuhan, dan gerakan [3]

Pesantren kerap diartikan sebagai asrama tempat santri atau tempat muridmurid belajar mengaji dan sebagainya [4]. Pondok pesantren di Indonesia memiliki peranan penting sebagai lembaga penyebaran agama sekaligus keceradasan rakyat dan moral bangsa. Dapat dikatakan bahwa pondok pesantren memiliki tujuan ganda sebagai institusi yang mempertahankan nilai-nilai keislaman dengan titik berat pada aspek pendidikan. Sedangkan dalam dunia pendidikan sendiri, aspek teknologi tidak bisa dipisahkan sebagai penunjang sistem belajar. Pada saat ini masih terlihat bahwa pesantren dikelola secara tradisional apalagi dalam penguasaan informasi dan teknologi yang masih belum optimal [5].

Dan pesantren sebagai lembaga pendidikan Islam mengalami perkembangan bentuk sesuai dengan perubahan zaman serta adanya dampak kemajuan ilmu bahan pengetahuan dan teknologi untuk mewujudkan maka kegiatan pelatihan yang akan dilaksanakan merupakan kegiatan pelatihan mikrontroler berbasis arduino sebagai pengenalan dunia teknologi di pondok pesantren agar bisa berkembang dengan sekolah pada umumnya.

Kegiatan pelatihan yang akan dilaksanakan ini merupakan kegiatan pelatihan gratis aplikasi mikrokontroler berbasis arduino yang dimotori oleh para Dosen-Dosen Teknik Elektro guna melatih dan menumbuhkan minat para santri untuk bisa mengikuti perkembangan teknologi khususnya mikrokontroler. Adapun tujuan pemberdayaan dari kegiatan ini merupakan suatu konsep untuk memberikan pengembangan diri para santri agar bisa paham teknologi yang sedang berkembang saat ini agar bisa dimanfaatkan dalam kehidupan sehari-hari. Dari rasa kepedulian itulah, kami terpanggil 
untuk pelatihan aplikasi mikrokontroler berbasis arduino dengan pengembangan pelatihan ini gratis untuk para santri.

\section{METODE/PERANCANGAN KEGIATAN}

Metode pelaksanaan yang digunakan dalam pelaksanaan PKM dapat dilihat pada diagram alir berikut

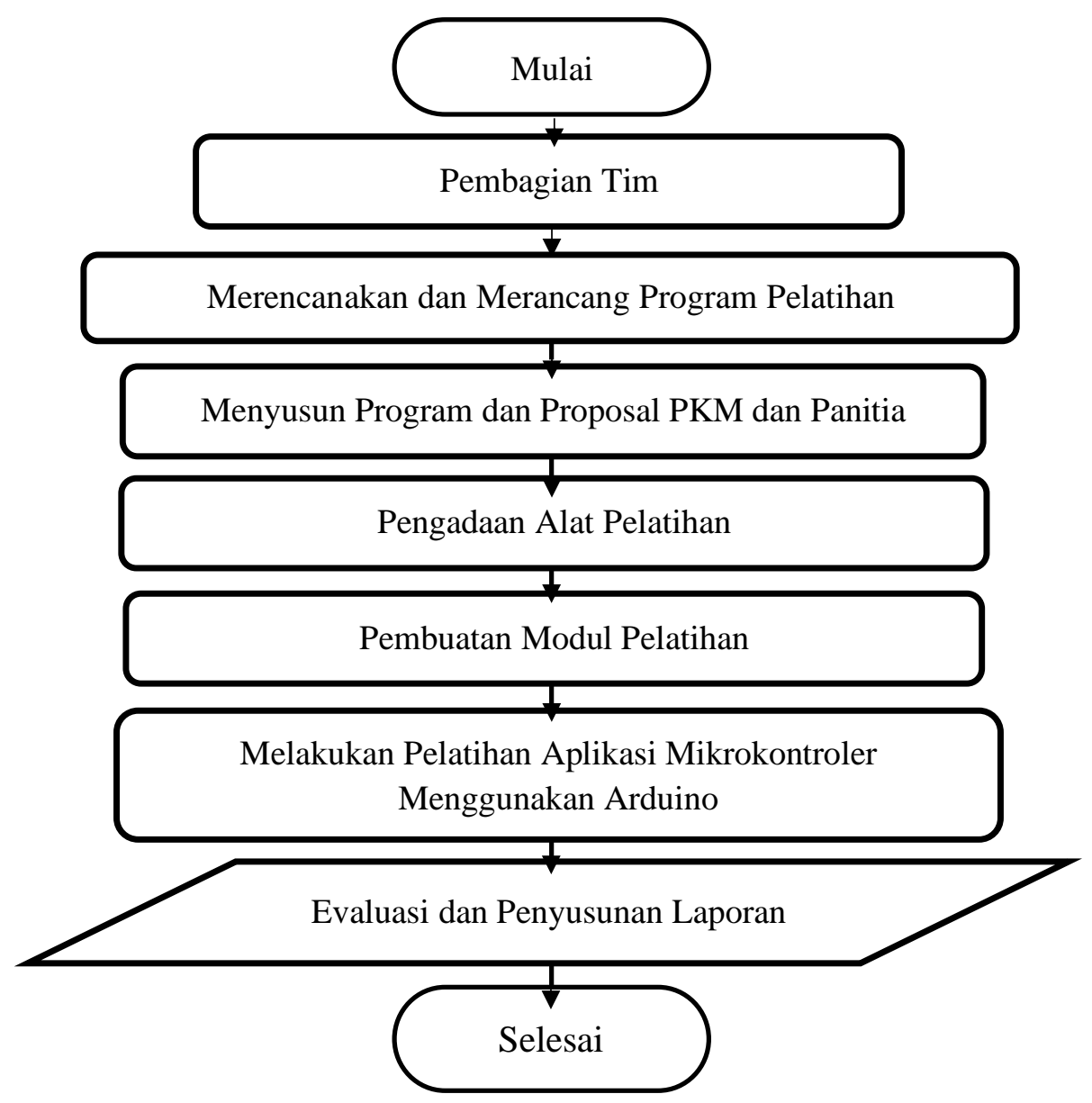

Gambar 1. Diagram Alir Metode Pelaksanaan Program

Pelatihan aplikasi mikrokontroler dengan menggunakan Arduino bertujuan untuk memperkenalkan teknologi mikrokontroler sebagai penunjang dalam peningkatan keamanan di dalam peralatan elektronika dan aplikasinya kepada siswa dan siswi di Madrasah Aliyah, Pondok Pesantren Darussalam Parung, Bogor. Pelatihan tersebut akan dilakukan dalam dua sesi pelatihan yang dibagi beberapa kelompok. Sesi pertama adalah pengenalan arduino dan pembuatan lampu hias LED. Sesi kedua adalah pembuatan jam digital. Masing-masing kelompok akan diberikan satu set peralatan yang digunakan untuk praktek. Siswa diberi modul pelatihan agar lebih mudah dan dapat digunakan untuk praktik mandiri.

Secara umum, langkah-langkah di dalam pelatihan aplikasi mikrokontroler dengan menggunakan arduino adalah sebagai berikut:

a) Langkah 1 : Pembukaan dan penjelasan mengenai kegiatan secara keseluruhan 
b) Langkah 2 : Penjelasan terkait teori tentang lampu hias LED, jam digital, dan arduino.

c) Langkah 3 : Penyajian dan peragaan alat rangkaian serta komponen-komponen.

d) Langkah 4 : Siswa-siswa diberi kesempatan untuk merangkai sendiri dengan didampingi dosen.

e) Langkah 5 : Siswa diberikan sertifikat kepesertaan pelatihan pembuatan lampu hias led dan jam digital dengan menggunakan arduino.

\section{HASIL DAN PEMBAHASAN}

Kegiatan kemitraan dengan tema pelatihan aplikasi mikrokontroler berupa pembuatan lampu hias LED dan jam digital dengan arduino di Pesantren Daarussalaam Parung Bogor ini diberikan secara gratis kepada santri-santriwati. Kegiatan ini dilakukan dengan dua sesi. Sesi pertama ada sesi pelatihan pembuatan lampu hias dilanjutkan dengan sesi kedua adalah pembuatan jam digital.

Kegiatan diawali dengan pembukaan yang diisi dengan sambutan dari pihak pesantren dan dari pihak STT-PLN. Dari pihak STT- PLN menjelaskan secara umum kegiatan yang akan dilakukan dan dari pihak pesantren mengucapkan terima kasih atas bantuan kegiatan yang diberikan oleh STTPLN. Kegiatan ini dihadiri oleh 49 peserta dengan jumlah santri putra 14 orang dan santri putri 35 orang. Kegiatan dilakukan di aula pesantren seperti terlihat pada Gambar 2.

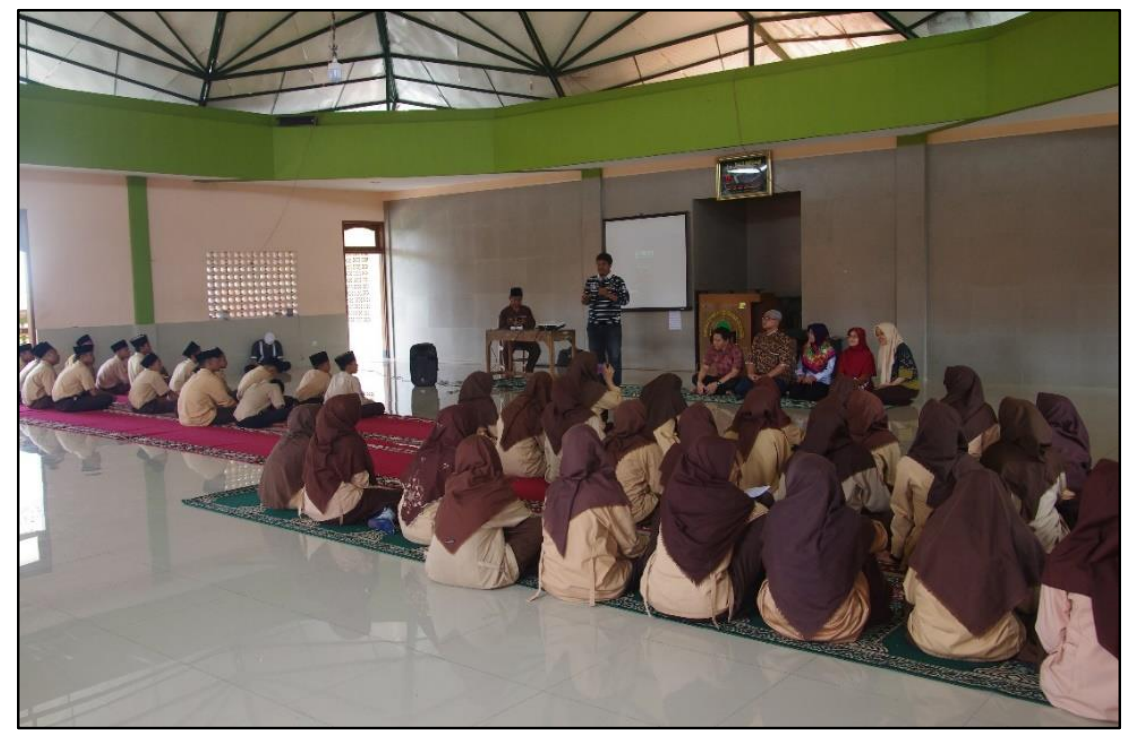

Gambar 2. Sambutan dan Penjelasan Mengenai Arduino

Setelah proses pembukaan selesai dilakukan proses penjelasan Arduino dan perakitan. 49 orang dibagi dalam 6 kelompok yang masing-masing didampingi seorang dosen (Gambar 3). Karena ini di lingkungan pesantren, maka santri putra dan santri putri dibedakan kelompoknya. Pada sesi pembuatan lampu hias, para peserta diminta untuk merakit sendiri lampu led dan komponen lainnya di board yang telah disediakan. Adapun langkah-langkah yang harus dilakukan oleh peserta sebagai berikut:

a) Pasang LED dan resistor pada Breadboard.

b) Hubungkan Arduino dengan laptop/computer.

c) Hubungkan Arduino, LED, dan resistor dengan kabel. 
d) Letakkan LED berjejeran dan masing-masing hubungkan dengan pin arduino 2 hingga pin 6.

e) Buka software Arduino IDE, ketik kode.

f) Pilih menu "Tools" > Pilih "Ports" > pilih COM yang sesuai

g) Klik Upload pada Arduino IDE, LED akan menyala bergantian.

Setelah berhasil, masing-masing kelompok kemudian mencoba mengubah-ubah parameterparameter di program mereka sesuai yang mereka inginkan. Pada Gambar 4, para santri putra terlihat menunjukkan hasil dari rakitannya

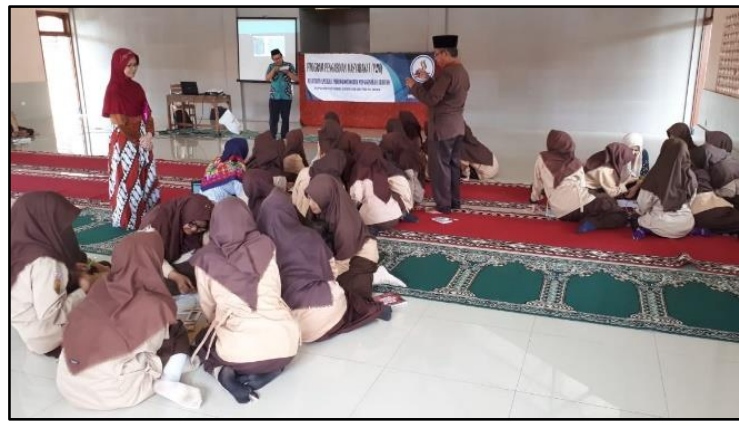

(a)

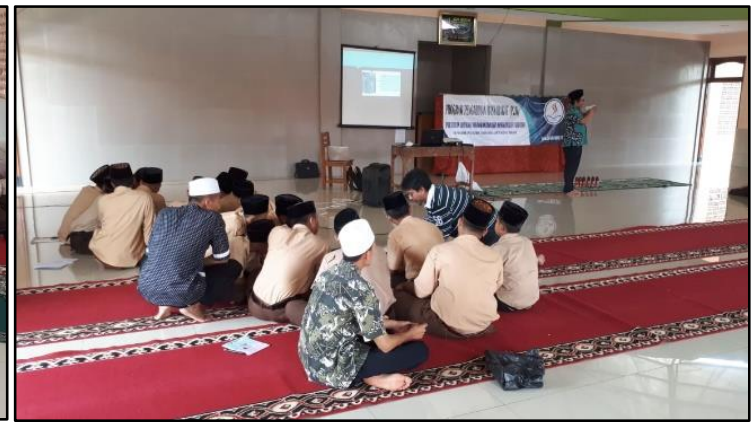

(b)

Gambar 3. Proses Penjelasan Arduino dan Prakteknya (a) Santri Putri (b) Santri Putra

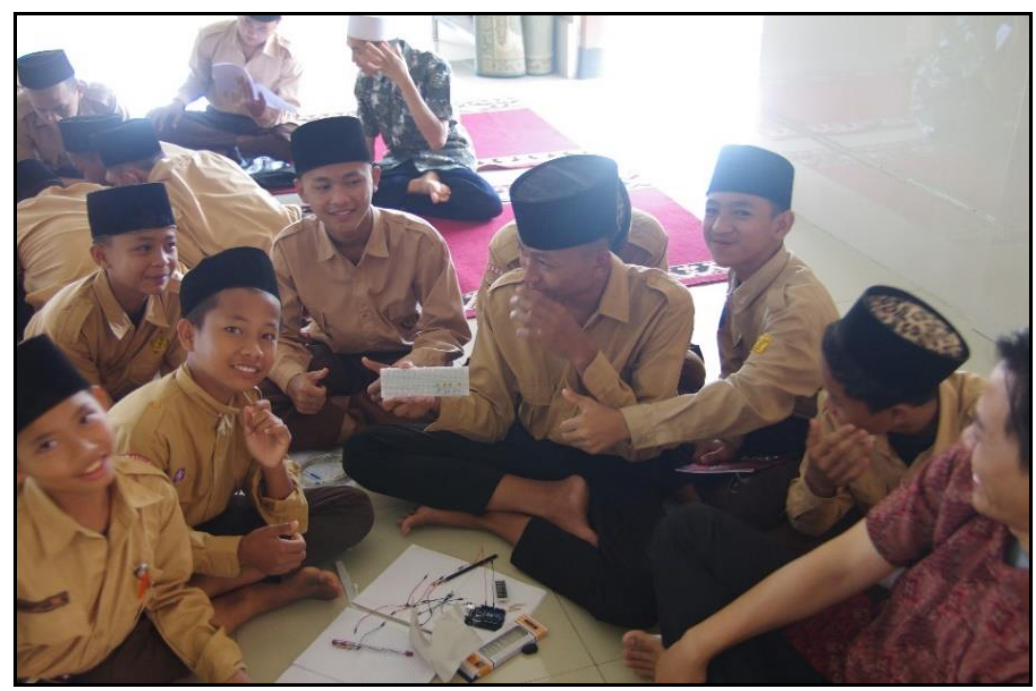

Gambar 4. Santri Putra Menunjukkan Hasil Rakitannya Lampu LED Hias

Setelah sesi pembuatan lampu hias led, dilanjutkan dengan sesi pembuatan jam digital. Adapun langkah dalam pembuatan digital adalah sebagai berikut:

1. Hubungkan Arduino dengan laptop/komputer

2. Dengan menggunakan kabel penghubung male female hubungkan pin pada seven segment dengan pin arduino. Lihat Tabel 1. untuk menghubungkan, Gambar 5 untuk melihat pin pada seven segment. 


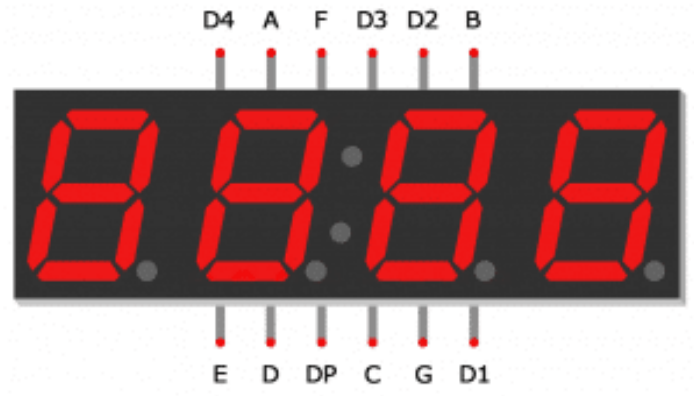

Gambar 5. Pin Seven Segment 4 Digit

Tabel 1. Hubungan Pin Arduino dan Seven Segment

\begin{tabular}{|l|l|l|l|}
\hline Pin Arduino & $\begin{array}{l}\text { Seven } \\
\text { Segment }\end{array}$ & Pin Arduino & Seven Segment \\
\hline 2 & A & 8 & G \\
\hline 3 & B & 9 & D1 \\
\hline 4 & C & 10 & D2 \\
\hline 5 & D & 11 & D3 \\
\hline 6 & E & 12 & D4 \\
\hline 7 & F & 13 & DP \\
\hline
\end{tabular}

3. Buka software Arduino IDE, Ketik Code

4. Pilih menu "Tools" > Pilih "Ports" > pilih COM yang sesuai

5. Klik Upload, dan Seven segment bekerja

Setelah berhasil membuat dan menjalankan jam digital, masing-masing kelompok kemudian mencoba mengubah-ubah program sehingga lebih paham.

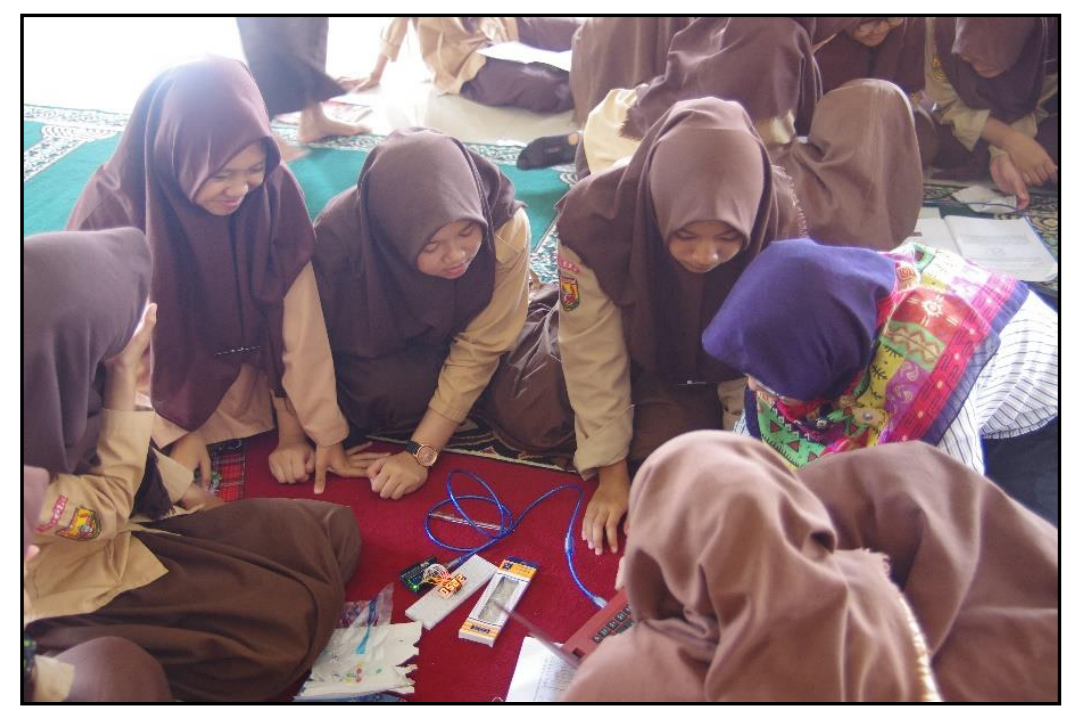

Gambar 5. Santri Putri Membuat Jam Digital dibantu Dosen

Di akhir kegiatan para peserta berfoto bersama dengan dosen dan guru pendamping seperti pada Gambar 6. 


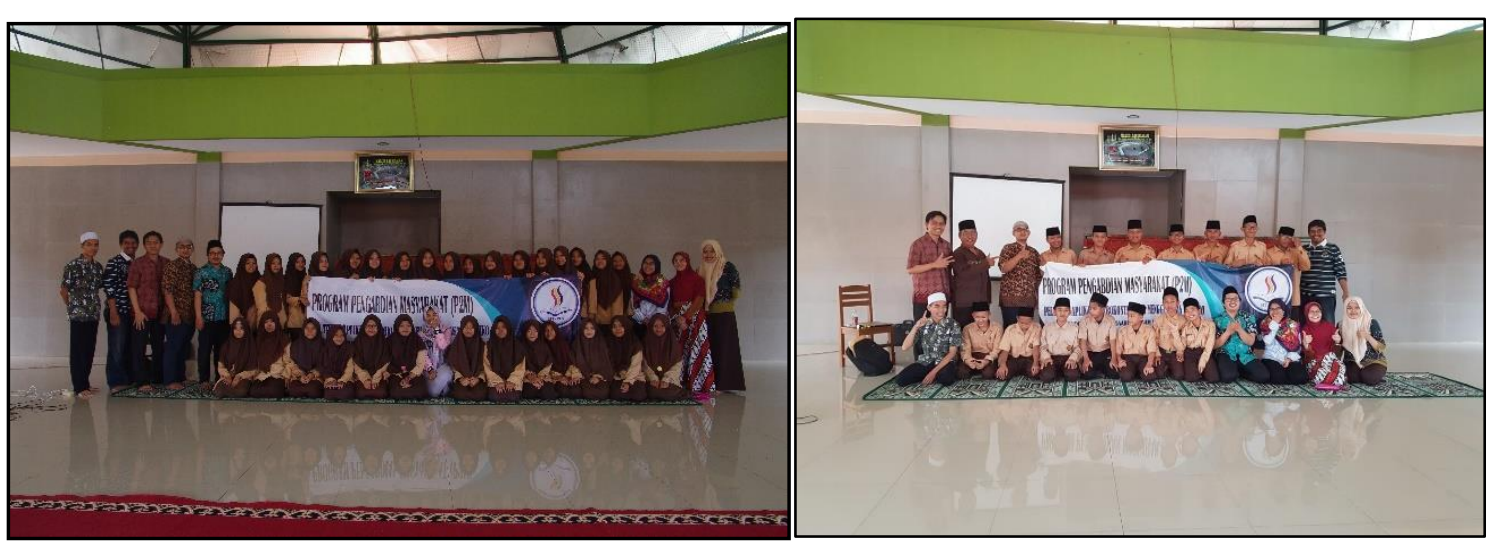

Gambar 6. Foto Bersama Setelah Pelatihan

Pada kegiatan kali ini terdapat beberapa evaluasi yang perlu dilakukan untuk kegiatan selanjutnya, antara lain:

1. Jumlah peserta per kelompok maksimal tiga orang. Dengan begitu, seluruh siswa bisa merasakan bagaimana membuat sebuah alat dengan arduino.

2. Percobaan dilakukan tidak hanya dengan membuat lampu hias dari led dan jam digital, tetapi juga percobaan-percobaan lain yang bisa menggunakan arduino sehingga kemampuan peserta semakin terasah.

3. Pendalaman tentang bagaimana membuat program arduino sehingga lebih banyak lagi produk yang bisa dibuat oleh santri.

\section{KESIMPULAN}

Dengan diadakannya kegiatan ini, santri dari Pondok Pesantren Daarussalaam dapat meningkatkan pengetahuannya tentang teknologi terbaru, terutama tentang mikrokontroler, dalam hal ini adalah arduino. Mereka juga dapat membuat secara mandiri lampu hias dari led dan juga jam digital. Sekolah juga dapat menggunakannya untuk kegiatan praktek di sekolah yang didampingi secara langsung oleh guru mereka.

\section{SARAN}

Kegiatan ini dapat dikembangkan dengan berbagai bentuk aplikasi lain menggunakan arduino. Selain itu, santri diharapkan dapat membuat lampu hias led dan jam digital yang dapat diproduksi dan dijual. Sehingga, ada pemasukan lebih bagi pesantren dari kreativitas santri.

\section{UCAPAN TERIMAKASIH}

Ucapan terima kasih disampaikan kepada mitra dalam hal ini Pondok Pesantren Daarussalaam yang menyediakan waktu dan tempat kegiatan, STT PLN melalui LP3M dan Program Studi Teknik Elektro yang mendukung serta mendanai kegiatan PKM. Semoga kegiatan semacam ini dapat terus dilanjutkan dan ditingkatkan demi terciptanya masyarakat yang sejahtera, adil dan makmur dengan memanfaatkan teknologi.

\section{DAFTAR PUSTAKA}

[1] A. Kadir, Panduan Praktis Mempelajari Aplikasi Mikrokontroller dan Pemrogramannya Menggunakan Arduino, Yogyakarta: Andipublisher, 2013. 
[2] A. Smith, Introduction to Arduino - A piece of cake, New York: Cambridge University Press, 2011.

[3] M. Margolis, Arduino Cookbook, Sebastopol: O’Reilly Media, Inc.,, 2011.

[4] A. Muhakamurrohman, "PESANTREN:SANTRI, KIAI, DAN TRADISI," Jurnal Kebudayaan Islam, vol. 12, no. 2, p. 109, 2014.

[5] Hamruni dan S. W. Ricky, "EKSISTENSI PESANTREN DAN KONTRIBUSINYA DALAM PENDIDIKAN KARAKTER," Jurnal Pendidikan Agama Islam, vol. XIII, no. 2, 2016. 